\title{
QUOTATIONS FROM THE EPISTLES OF ST PAUL IN ST HILARY ON THE PSALMS.
}

The quotations made from the Epistles of St Paul in St Hilary's works are registered with such striking incompleteness in the standard edition, that of Verona ( 2 vols. folio, $173^{\circ}$ ), that no real idea of the extent to which they are quoted can be obtained by the reader. In the edition of the Homilies on the Psalms, which appeared in the Vienna Corpus in $189 \mathrm{r}$, and marked a real advance on its predecessor, no index of any sort is provided. For the past quarter of a century the student, who wished to find out the exact form in which St Hilary quoted the Epistles, has had to make his own index.

For various reasons this state of affairs is unsatisfactory. St Hilary is, of course, an author of first-rate importance from every point of view, that of Biblical text included. It happens also that his works are for the most part preserved in very old manuscripts, dating from the sixth century onwards. There is, therefore, a reasonable expectation that the quotations will be found exactly in the form in which he made them. Again, he is not merely the only important witness to the text of farther Gaul at his date, but there is an extreme probability that it was from his region and time that Great Britain and Ireland obtained Biblical texts which were in use in these islands for centuries after. We may expect some light to be thrown on the character of such texts by the study of St Hilary's quotations. An index of those quotations has also a value for the student of the history of interpretation: for example, the mysterious Ambrosiaster was certainly a close student of St Hilary. Finally, the index reveals what were St Hilary's favourite texts in the Epistles.

The index which follows was made for my own purposes, and it is printed here in the hope that it may save other scholars trouble. I have not meantime verified more than some of the references, but have taken them without examination from the rubrics in Zingerle's edition. The number indicates the page of his edition.

1 Sometimes certain of the numbers of pages following 'sq.' do not indicate that 'sq.' are there found. 
Romans.

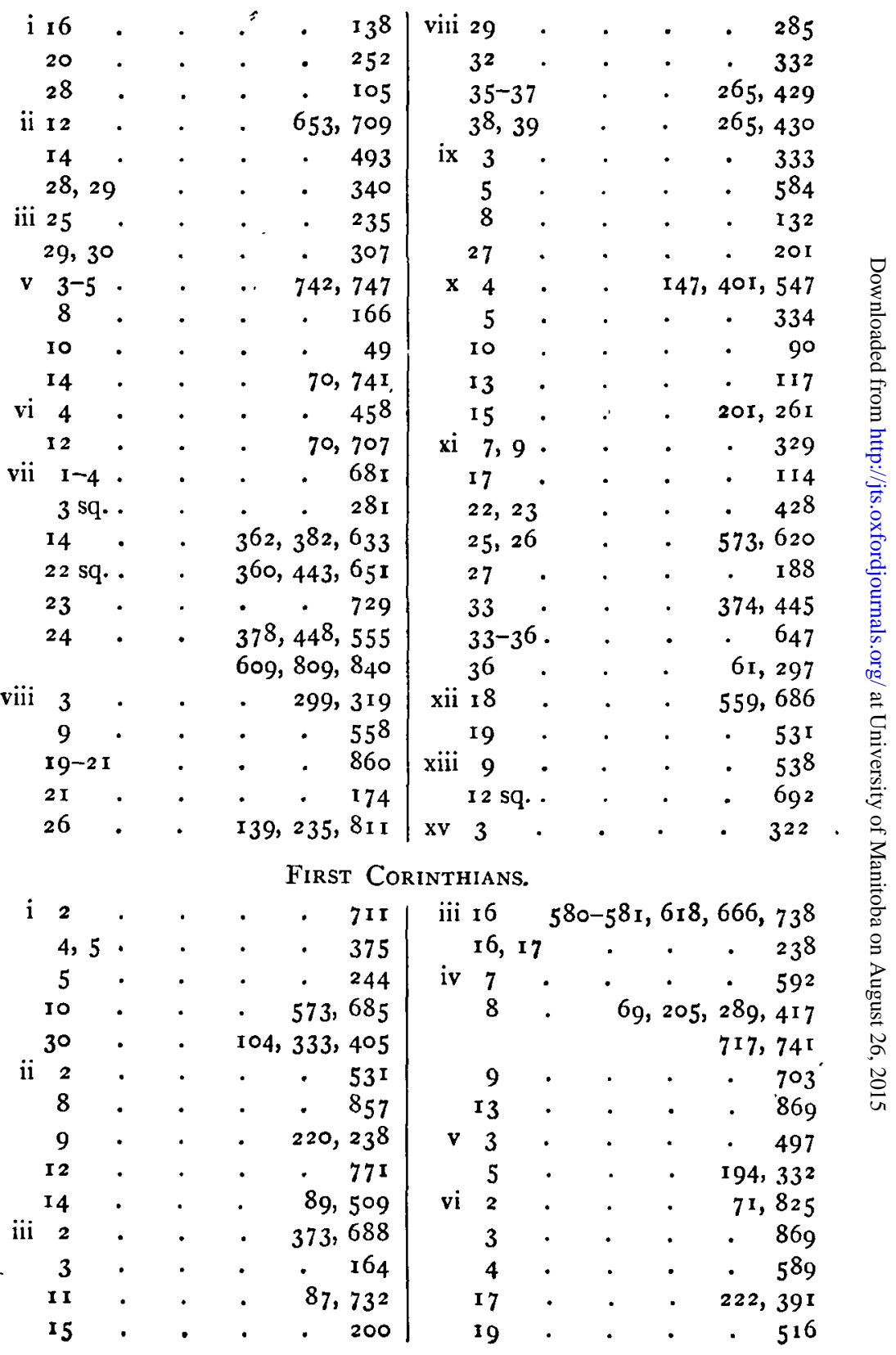




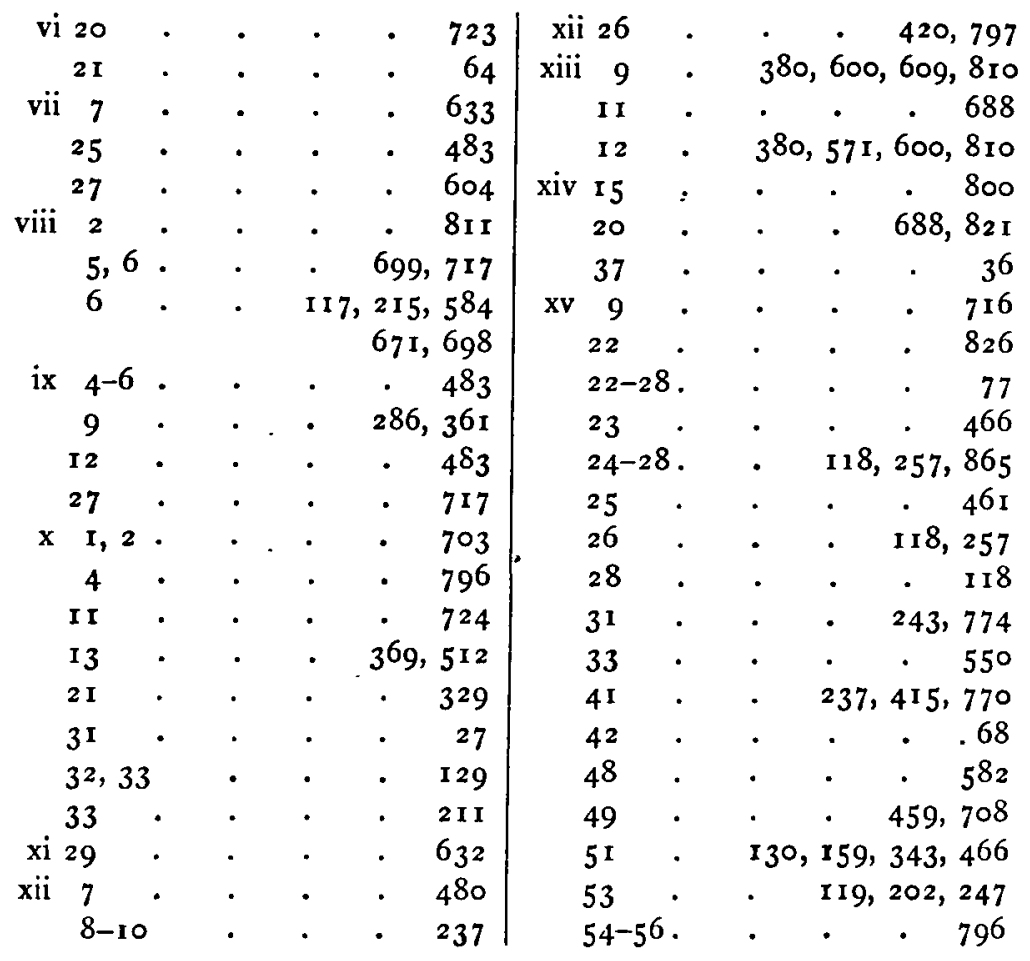

Second Corinthians.

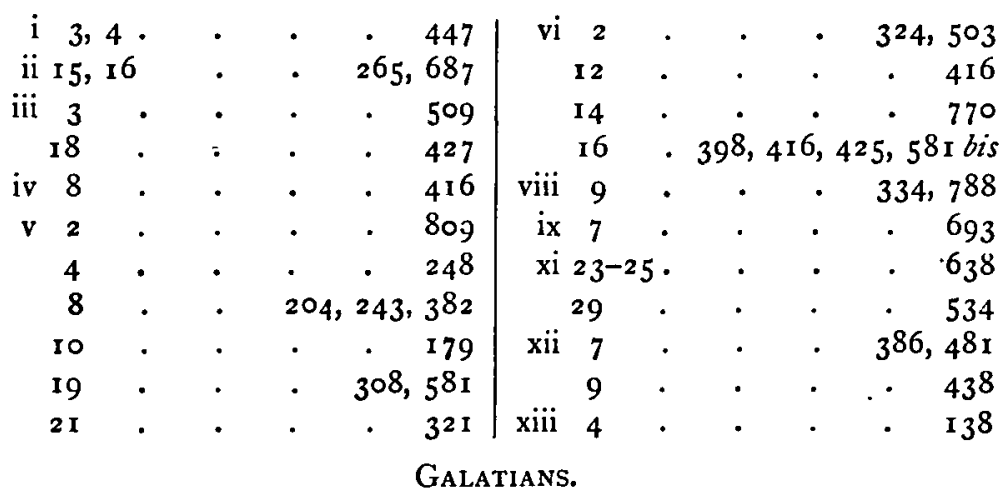

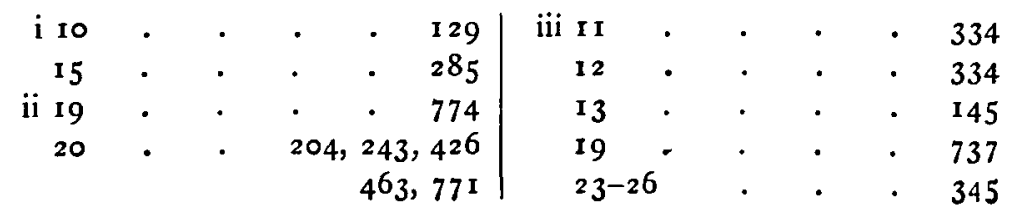




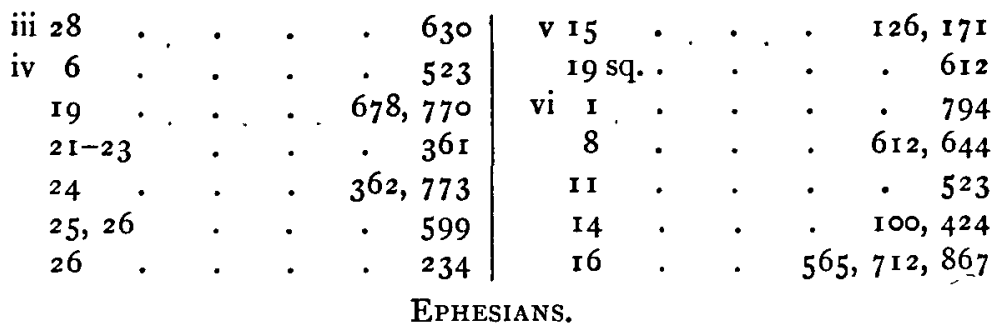

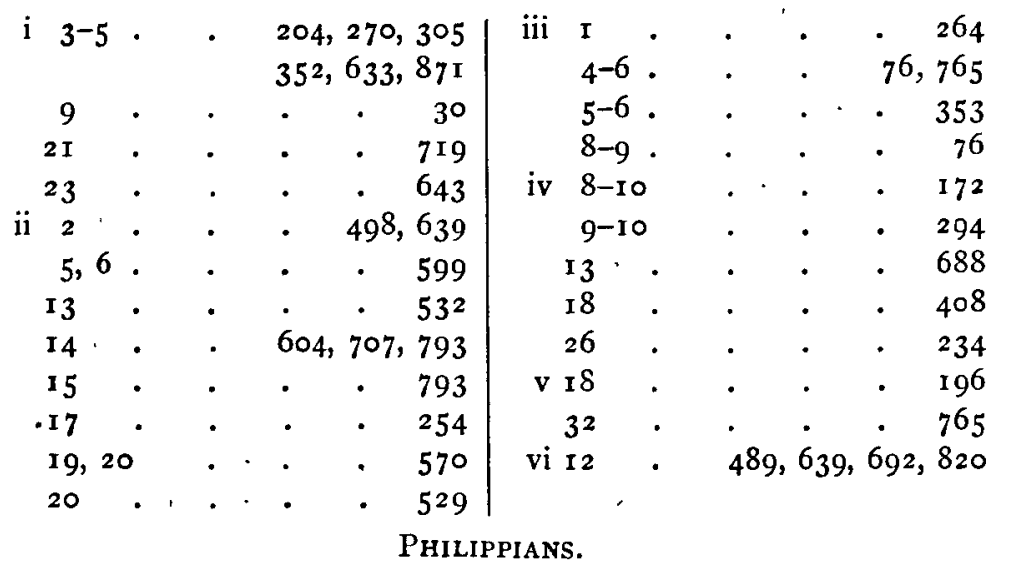

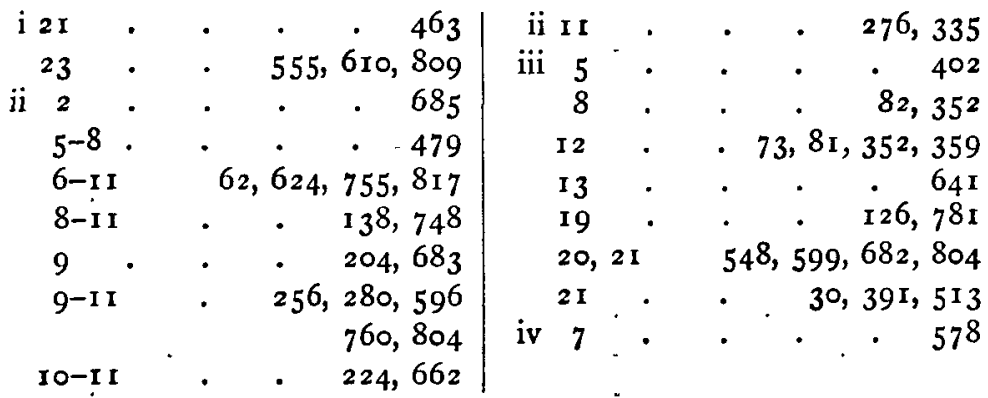

Colossians.

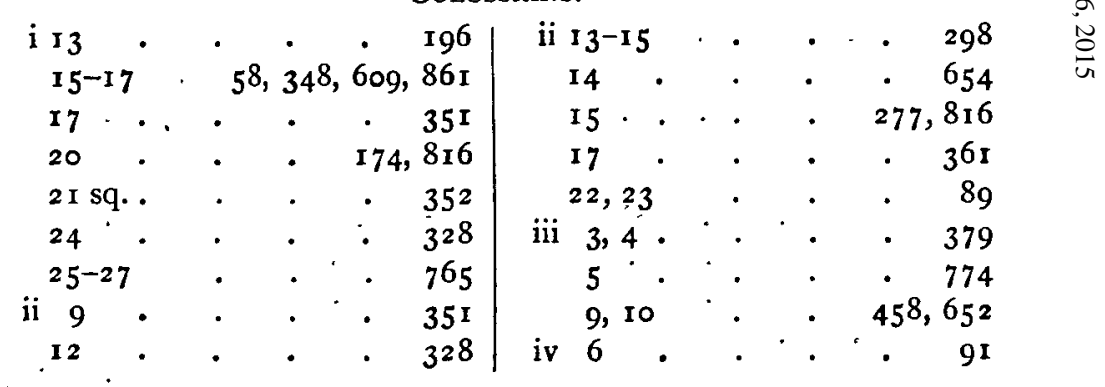


First Thessalonians.

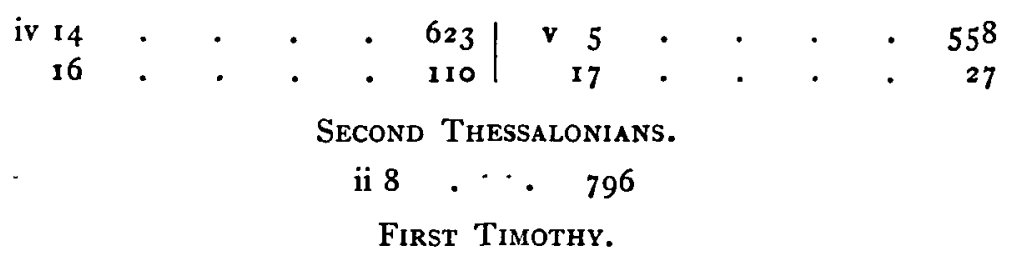

\begin{tabular}{|c|c|c|c|c|c|c|c|c|c|c|c|}
\hline i 20 & - & - & - & - & 497 & iv 14 & - & - & - & & $4 \sqrt{3}$ \\
\hline ii $\quad I$ & - & . & . & · & 790 & v 6 & - & - & - & & 283 \\
\hline 8 & - & - & . & & 791 & I I & - & - & - & & 282 \\
\hline iii & . & . & . & • & $3^{87}$ & $2 \mathrm{I}$ & . & - & - & $3^{6} 3$ & 486 \\
\hline 15 & - & - & I I 5 , & 237 & 685 & vi 15 & . & - & - & - & 717 \\
\hline
\end{tabular}

A. Souter.

\section{NOTES ON ORIGEN AND EUSEBIUS.}

I. Among the fragments of Origen published by Gallandi from Venice MSS. (Bibliotheca Veterum Patrum, vol. xiv) is one on Mt. xxvii 45, anonymous in his MS. This is clearly largely drawn from Origen's Commentary on Matthew, here extant only in an abridged Latin version; but the bulk of it is from Chrysostom's Commentary (Hom. 88). The first part of the fragment is mainly from Origen, possibly including some phrases where the Latin (Series 134 ) has nothing corresponding. Then comes a long passage from Chrysostom, then some more Origen, then a passage which may be his, then some more Chrysostom.

In Cramer's Catena there is a similar composite quotation at this point. Much in the two notes is the same, but Cramer's is shorter, and has more of Chrysostom. Both apparently use some writer, or catena, which combined these two writers. 
The Origen portions include a reference to Phlegon. The Latin runs 'Et Phlegon quidem in Chronicis suis scripsit in principatu Tiberii Caesaris factum, sed non significavit in luna plena hoc factum'. The

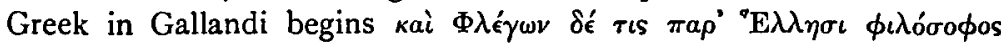

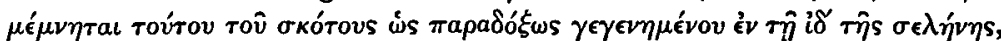

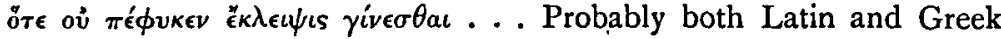
are abridgements of the original.

2. Eusebius's Eclogae Propheticae-really Books 6-9 of his General Elementary Introduction - comprise comments on Messianic Prophecies. They were published by Gaisford in 1842 from the unique MS. at Vienna.

I have not seen it noticed that Book II, dealing with passages in the Psalms, is very incomplete. It is much less than half the length of any of the other three books. Chapters $\mathrm{I}-\mathrm{I}_{3}$ deal with Psalms I-2I (22); 14-1 8 with Psalms I3I (2)-r 5o. Thus very many Psalms are omitted, including some which Eusebius was very likely to handle, as he does elsewhere-e.g. 69 and 72. On close examination of ch. 13 it is seen that the final sentence has no connexion with the rest. Eusebius's treatment of Psalm 2I (22) does not go beyond v. 19; what follows really belongs to the last part of Ps. I 7 (I I8), 'Hosanna'-with this compare Dem. Ev. vi 8 p. 266 , ix 18 p. 459 . Thus a large part of the book, from the middle of Ps. 2 I (22) to near the end of Ps. II 7 (I I 8 ) is lost. The break occurs at the end of f. $22 \mathrm{v}$. in the MS.; f. 23 begins with the fragment of Ps. II 7. Hence a predecessor of the MS. had clearly lost a number of leaves at this point.

Eusebius's treatment of Messianic Prophecies is, however, well represented in the Demonstration of the Gospel and his Commentary on the Psalms.

HAROLd SMith. 